\title{
Role of the Putative Polysaccharide Deacetylase BA1836 from B. anthracis in Spore Development and Germination
}

\author{
Anastasia Tomatsidou', Dimitris Koutsioulis ${ }^{2}$, Dimitris Tzamarias ${ }^{1}$, Michael Kokkinidis ${ }^{1,2}$, \\ Waldemar Vollmer ${ }^{3}$, Vassilis Bouriotis ${ }^{1,2 *}$ \\ ${ }^{1}$ Department of Biology Voutes, University of Crete, Heraklion, Greece \\ ${ }^{2}$ Institute of Molecular Biology \& Biotechnology, Foundation for Research and Technology, Heraklion, Greece \\ ${ }^{3}$ The Centre for Bacterial Cell Biology, Institute for Cell and Molecular Biosciences, Newcastle University, \\ Newcastle upon Tyne, UK \\ Email: *bouriotis@uoc.gr
}

How to cite this paper: Tomatsidou, A., Koutsioulis, D., Tzamarias, D., Kokkinidis, M., Vollmer, W. and Bouriotis, V. (2019) Role of the Putative Polysaccharide Deacetylase BA1836 from B. anthracis in Spore Development and Germination. Advances in Microbiology, 9, 679-702.

https://doi.org/10.4236/aim.2019.98042

Received: May 18, 2019

Accepted: August 4, 2019

Published: August 7, 2019

Copyright $\odot 2019$ by author(s) and Scientific Research Publishing Inc. This work is licensed under the Creative Commons Attribution International License (CC BY 4.0).

http://creativecommons.org/licenses/by/4.0/

\begin{abstract}
Putative and known polysaccharide deacetylases (PDAs) from B. anthracis have key roles in resistance to host lysozyme, stabilization of the cell wall, biogenesis of peptidoglycan (PG) and for neutral polysaccharide modification and attachment to PG. Here we elucidated the physiological role of the putative PDA BA1836 from B. anthracis. The ba1836 gene was expressed upon entrance into the stationary phase of growth and enhanced during the early stages of sporulation. The $\Delta b a 1836$ knockout strain had normal growth rate, did not exhibit any significant alterations in PG pattern of stationary phase cells and was not sensitive to lysozyme, but showed a defect in cell separation. Strikingly, the $\Delta b a 1836$ mutant strain exhibited a severe delay in spore development although mature spores were ultimately developed and had normal morphology. Additionally, digestion of $\Delta b a 1836$ mutant spore PG with mutanolysin produced an almost identical muropeptide pattern compared to peptidoglycan from wild type spores, although the amount of all muropeptides was significantly reduced. Finally, knockout spores exhibited a lower germination rate. To our knowledge, BA1836 has a unique role, among the presently characterized PDAs from $B$. anthracis, in spore development and germination.
\end{abstract}

\section{Keywords}

Bacillus anthracis, Polysaccharide Deacetylases, BA1836, Spores, Germination, Spore Development 


\section{Introduction}

The Gram-positive bacterium B. anthracis exists in two distinct cellular morphologies: the vegetative cell and the dormant spore, which is the infectious agent of the anthrax disease [1]. Sporulation is a tightly regulated developmental process during which several morphological events take place [2].

Like in other Bacillus species sporulation in B. anthracis is induced by nutrient depletion of vegetative cells in combination with other stress signals [3] [4]. Initially, a single rod shaped cell divides asymmetrically, resulting in two different daughter cells, the mother cell and the forespore. Subsequently, the mother cell engulfs the forespore, in a process similar to phagocytosis, followed by the assembly of the spore coat and cortex. When the spore is mature, it is released into the environment, upon lysis of the mother cell, where the dormant spore is highly resistant to a range of environmental insults [2] [5] [6].

In vegetative cells, the net-like peptidoglycan (PG) layer is made of glycan chains connected by short peptides and is essential for cell integrity, enabling the cell to resist the turgor and maintain its cell shape [7]. Spore PG consists of two layers: the thin, inner germ cell wall and the thick outer cortex layer [8]. The cortex contains unique structural modifications, such as muramic-delta-lactam residues [9], and contributes to the resistance of the spores against heat and chemicals [10]. During germination, the cortex is specifically degraded by germination-specific lytic enzymes (GSLEs), while the germ cell wall remains intact. PG from spores lacking muramic-delta-lactam cannot be hydrolysed by GSLEs [11]. Enzymes and precursors employed for the production of the germ cell wall and cortex PG layers exhibit different localization. Those required for germ cell wall synthesis are localized in the forespore, while those involved in cortex synthesis are localized in the mother cell [12].

PG $N$-acetylglucosamine (GlcNAc) deacetylation has been demonstrated to contribute to lysozyme resistance of vegetative cells in several pathogenic species [13] [14] [15]. Deacetylation of spore PG has been also demonstrated, albeit at reduced levels compared to vegetative cells [16], but it is not associated with lysozyme resistance, since the main mechanism of spore lysozyme resistance is the permeability barrier of the spore coat layers [17].

After entry to a suitable host, the $B$. anthracis spore undergoes germination, which is the earliest pathogenic event, followed by the production of deadly toxins [18] [19]. Initiation of germination depends on interactions of small molecule nutrients, termed germinants, with receptors located within the inner endospore membrane [20]. Subsequently, calcium-dipicolinic acid (Ca-DPA) is released from the spore core thus initiating rehydration. Finally, GSLEs hydrolyse the spore cortex PG, leading to full rehydration of the core and resumption of metabolism [21] [22].

Polysaccharide deacetylases (PDAs) are members of the carbohydrate esterase family 4 (CE4) which consists of acetylxylan esterases, chitin, chitooligosaccharide and PG deacetylases. Members of this family catalyze the hydrolysis of either $N$-linked acetyl group from GlcNAc residues (chitin, chitooligosaccha- 
ride, and PG GlcNAc deacetylase) [13] [23] or $O$-linked acetyl group from O-acetylxylose residues (acetylxylan esterase) [24] [25] [26]. They are metal dependent enzymes and share a conserved catalytic core termed the NodB homology domain.

Interestingly, the genomes of Bacillus sp., and especially of B. cereus sensu lato, including $B$. anthracis, contain multiple putative PDA genes with high sequence homologies. The physiological role of seven of these from $B$. anthracis has been elucidated [27] [28]. BA1977 similarly to PG GlcNAc deacetylases (PGDAs) of other bacteria is involved in resistance to host lysozyme and required for full virulence. BA1961 and BA3679 participate in the biogenesis of the PG during both elongation and cell division, while BA5436 and BA2944 are important for neutral polysaccharide attachment to PG and for polysaccharide modification respectively [27]. Finally, BA0330 is important for the adaptation of the bacterium to grow in the presence of a high concentration of salt, whereas BA0331 contributes to the maintenance of a uniform cell shape [28]. Due to their crucial roles in $B$. anthracis physiology, inhibitors targeting their conserved active sites have been developed [29].

Presently, there is limited information on PDAs affecting either sporulation or germination of bacteria. Two PDAs from B. subtilis, PdaA and PdaB have been demonstrated to affect sporulation and germination of this bacterium. Absence of PdaA, a PG $N$-acetylmuramic acid (MurNAc) deacetylase from B. subtilis, results in complete lack of spore germination due to deficiency in muramic-delta-lactam formation, one of the major components of the spore cortex [30]. The absence of PdaB results in empty or cortex-less spores, implying its importance in cortex formation and further maintenance of spores after the late stage of sporulation [31].

In this study we used genetic (knock-out) analysis, protein localization as well as spore and germination assays to elucidate the function of the putative PDA BA1836 from $B$. anthracis. We show that this protein has a unique role among the presently characterized putative and known PDAs of $B$. anthracis in promoting normal spore development and germination.

\section{Materials and Methods}

\subsection{Bacterial Strains and Growth Conditions}

The strains and plasmids used in this study are listed in Table S1. E. coli strains were grown in Luria Bertani (LB) medium and B. anthracis strains in Brain Heart Infusion (BHI) medium. Sporulation was induced by resuspension in modified G medium [32] [33] and mature spores were formed after plating of vegetative cells on Spizizen Yeast (SPY) agar medium which when required was supplemented with $0.2 \%$ xylose.

\subsection{Construction of B. anthracis $\Delta b a 1836$ Knockout Strain, GFP Fusion and lacZ Transcriptional Fusion}

A strain bearing an in-frame deletion of ba1836 gene was created using a mar- 
kerless gene replacement method [34]. In brief, DNA fragments containing the sequence upstream and downstream of bal836 gene were amplified from genomic DNA of $B$. anthracis 7702 [35] by PCR using the appropriate oligonucleotides (Table S2). Both fragments were cloned into the same pGEM vector and the upstream-downstream fragment was digested with SacI/KpnI and ligated into pRP1028 vector. E. coli HB101 [36] was used as helper strain in order to primarily introduce pRP1028 construct [37] and subsequently pSS4332 vector [37], which encodes the I-SceI enzyme, into $B$. anthracis 7702 strain. Finally, the knockout strain had no resistance to antibiotics and was validated for the correct construction by PCR.

To construct strains expressing GFP translational fusions, the gfp-mut1 gene was amplified from pNF8 [38] with specific primers, digested with NruI and BglII, and ligated into the xylose-inducible plasmid pWH1520 [39]. Then, ba1836 (lacking the stop codon) was amplified from B. anthracis 7702 chromosomal DNA with the appropriate primers to incorporate at the $\mathrm{C}$ terminus the polylinker GPGP. The amplicon was digested with BamHI and NruI and ligated in-frame to the 5 ' end of gfp-mut1, placing the gene fusion under a $x y$ lose-inducible promoter. E. coli GM48 ( $\left.\mathrm{dam}^{-}\right)$was transformed with the resulting construct to obtain nonmethylated plasmid DNA for electroporation [40] into 7702 and $\Delta$ ba1836 B. anthracis cells. $10 \mathrm{ml}$ of BHI medium were inoculated from overnight cultures to an $\mathrm{OD}_{600 \mathrm{~nm}}$ of 0.05 and incubated at $37^{\circ} \mathrm{C}$. For ba1836-gfp expressing strains, induction was achieved with $0.2 \%$ xylose (for expression from the xylose-inducible promoter) $1 \mathrm{~h}$ before the culture reached early stationary phase of growth $\left(\mathrm{OD}_{600 \mathrm{~nm}}\right.$ around 3.0).

In order to create the lacZ-transcriptional fusion, a DNA fragment of the upstream region of bal836 gene was amplified from B. anthracis 7702 chromosomal DNA. Primers were synthesized to incorporate a HindIII site at the start and a BamHI site at the end of the amplified fragment (Table S2), which was digested with the corresponding enzymes, and ligated into the multicopy replicative vector pHT304-18Z [41]. In this way, a lacZ reporter construct with the upstream region of each gene fused directly to the start codon of the lac $Z$ gene was obtained. E. coli GM48 ( $\mathrm{dam}^{-}$) was transformed with the resulting construct to obtain nonmethylated plasmid DNA for electroporation [40] into 7702 B. anthracis cells.

\subsection{Site-Directed Mutagenesis of ba1836 Gene}

A mutant of the ba1836 gene was constructed using a two-step/four-primer overlap extension PCR method [42]. Primers used in this method are listed in Table S2. The amplified ba1836 product was cloned into pWH1520 vector as described above.

\subsection{Preparation of Sporulating Cell Cultures}

$10 \mathrm{ml}$ of BHI medium were inoculated from overnight cultures of 7702 parental 
and $\Delta$ ba1836 mutant strains to an $\mathrm{OD}_{600 \mathrm{~nm}}$ of 0.05 and incubated at $37^{\circ} \mathrm{C}$. When $\mathrm{OD}_{600 \mathrm{~nm}}$ of the cultures reached 1.2 (mid-exponential phase) or 3.0 (early stationary phase), the cultures were centrifuged for $20 \mathrm{~min}$ at $2570 \mathrm{~g}$ and sporulation was induced by resuspension of the cell pellet in an equal volume of modified $G$ medium. The cultures were then transferred to $30^{\circ} \mathrm{C}$. Cells were collected at frequent time intervals and observed under optical and fluorescence microscopy.

\section{5. $\beta$-Galactosidase Activity Assay}

Cell samples were collected in triplicates from shaking cultures at various time points during vegetative growth or sporulation. $\mathrm{OD}_{600 \mathrm{~nm}}$ for each cell sample was recorded before collection. $\beta$-galactosidase activity was measured as described by Camp and Losick [43] with minor changes. Cells pellets corresponding to $1 \mathrm{ml}$ of the original sporulation medium were resuspended in $0.2 \mathrm{ml} \mathrm{Z}$-buffer $(60 \mathrm{mM}$ $\mathrm{Na}_{2} \mathrm{HPO}_{4}, 40 \mathrm{mM} \mathrm{NaH}_{2} \mathrm{PO}_{4}, 10 \mathrm{mM} \mathrm{KCl}, 1 \mathrm{mM} \mathrm{MgSO}$, $50 \mathrm{mM} \beta$-mercaptoethanol $\mathrm{pH}$ 7.0). $50 \mu \mathrm{l}$ of the cell suspension were added to individual wells of a 96-well plate containing $15 \mu \mathrm{l}$ of $0.1 \%$ SDS and were incubated at $37^{\circ} \mathrm{C}$ for $30 \mathrm{~min} .20 \mu \mathrm{l}$ of $4 \mathrm{mg} \cdot \mathrm{mL}^{-1} 2$-nitrophenyl $\beta$-D-galactopyranoside (ONPG) in Z-buffer were then added to each well and mixed thoroughly. Absorbance at $420 \mathrm{~nm}$ for each reaction was read once per minute for $1 \mathrm{~h}$ at $37^{\circ} \mathrm{C}$ in a Fluostar Galaxy plate reader. $\beta$-galactosidase activity is expressed in Miller units (MU) [44] [45].

\subsection{Fluorescence Microscopy, Scanning and Transmission Electron Microscopy}

B. anthracis sporulating cell cultures of 7702 parental and $\Delta$ ba1836 knockout strains were examined by optical and fluorescence microscopy. For membrane visualization the FM4-64 fluorescent dye was added to a final concentration of 1 $\mu \mathrm{g} \cdot \mathrm{ml}^{-1}$. Sporulating cells in stages II and III were stained with FM4-64 in order to visualize the assymetric septum and engulfment respectively. Optical microscopy was used after stage III of sporulation when the forespore is formed. $B$. anthracis vegetative cell cultures of 7702 overexpressing the ba1836-gfp fusion were examined by fluorescence microscopy. The images were obtained without fixation on an inverted epifluorescence microscope Nikon E800. Preparation of cell samples for scanning and transmission electron microscopy was performed according to Arnaouteli et al. [28]. Samples were examined using a JEOL JSM-6390LV scanning electron microscope, operating at $20 \mathrm{kV}$. Sections were observed in a JEOL, JEM 2100 transmission electron microscope, operated at 80 $\mathrm{kV}$.

\subsection{In Vitro Determination of Lysozyme Sensitivity}

To test the sensitivity of $\Delta b a 1836$ mutant strain in the presence of exogenously added lysozyme, overnight cultures of the parental and mutant strains were diluted to an $\mathrm{OD}_{600 \mathrm{~nm}}$ of 0.1 into 2 cultures of $20 \mathrm{ml}$ of fresh SPY medium for each strain. The cultures were incubated at $37^{\circ} \mathrm{C}$ until an $\mathrm{OD}_{600 \mathrm{~nm}}$ of 1.2 and 3.0 cor- 
responding to mid-exponential and early stationary phase of growth respectively. Then each culture was divided in two equal parts of $10 \mathrm{ml}$, and $10 \mu \mathrm{g} \cdot \mathrm{ml}^{-1}$ hen egg lysozyme was added to one of the two subcultures. The growth of both treated and untreated subcultures was monitored.

\subsection{Autolysis Assay}

Autolysis assay was performed according to Balomenou et al. [27] with minor changes. Cultures of $10 \mathrm{ml}$ SPY of 7702 and $\Delta$ ba1836 cells at an $\mathrm{OD}_{600 \mathrm{~nm}}$ of 3.0 were centrifuged for $20 \mathrm{~min}$ at $2570 \mathrm{~g}$ and the bacterial pellet was concentrated 10 times in SPY medium to which $10 \mathrm{mM} \mathrm{NaN}_{3}$ was added. The decrease of $\mathrm{OD}_{600 \mathrm{~nm}}$ of each culture was monitored every $30 \mathrm{~min}$ for a period of $180 \mathrm{~min}$.

\subsection{PG Purification}

PG from the parental strain 7702 and $\Delta$ ba1836 mutant was purified from stationary growing bacteria (in SPY) as well as from spores, as previously described [46] [47]. Muropeptides were generated from $0.2 \mathrm{mg}$ of spore or vegetative cell PG by digestion with mutanolysin (Sigma) at $37^{\circ} \mathrm{C}$ for $16 \mathrm{~h}$ and separated by HPLC as previously described [48].

\subsection{Competition Experiments}

In order to perform competition experiments, a lac $Z$ reporter construct with the eag promoter ( $P$ eag) fused directly to the start codon of the lac $Z$ gene was built. The Peag [49] was amplified from B. anthracis 7702 chromosomal DNA. Primers were synthesized to incorporate a HindIII site at the start and a BamHI site at the end of the Peag (Table S2), which was digested with the corresponding enzymes, and ligated into the multicopy, replicative vector pHT304-18Z. E. coli GM48 ( $\left.\mathrm{dam}^{-}\right)$was transformed with the resulting construct to obtain nonmethylated plasmid DNA for electroporation [40] into 7702 B. anthracis cells.

Competition experiments were performed according to Traag et al. [45] with a few changes. Briefly, starting from overnight BHI culture, 7702 strain containing pHT304-18Z-Peag construct was mixed, either in 1:1 or 1:3 ratio with mutant $\Delta$ bal 836 strain containing pHT304-18Z vector in $5 \mathrm{ml}$ modified $\mathrm{G}$ medium. Cultures were grown and allowed to sporulate at $30^{\circ} \mathrm{C}$ for $48 \mathrm{~h}$. The cultures were then heat treated at $80^{\circ} \mathrm{C}$ for $20 \mathrm{~min}$, briefly cooled at room temperature and inoculated in $5 \mathrm{ml}$ fresh modified $\mathrm{G}$ medium. Before inoculation, cultures were diluted and plated on agar plates containing $40 \mu \mathrm{g} \cdot \mathrm{ml}^{-1}$ 5-bromo-4-chloro-3-indolyl- $\beta$-D-galactopyranoside (X-Gal) and $5 \mu \mathrm{g} \cdot \mathrm{ml}^{-1}$ erythromycin. The blue and white colonies were counted. Similarly, competition experiments were performed for vegetative phase of growth. Briefly, starting from overnight BHI culture, 7702 strain containing pHT304-18Z-Peag construct was mixed in 1:1 ratio with mutant $\Delta b a 1836$ strain containing pHT304-18Z vector in $5 \mathrm{ml} \mathrm{BHI} \mathrm{medium.} \mathrm{Cultures} \mathrm{were} \mathrm{grown} \mathrm{at} 30^{\circ} \mathrm{C}$ for $24 \mathrm{~h}$ and then inoculated in $5 \mathrm{ml}$ fresh BHI medium [45]. 


\subsection{Spore Preparation and Purification}

Single colonies from 7702 and $\triangle$ ba1836 B. anthracis strains were streaked onto SPY agar plates supplemented with $0.2 \%$ glucose and $10 \mathrm{mM} \mathrm{MgSO}_{4}$ and left to sporulate for 7 days at $30^{\circ} \mathrm{C}$. When needed, the SPY agar plates were additionally supplemented with $0.2 \%$ xylose.

Spores were harvested in water, centrifuged at $5900 \mathrm{~g}$ for $5 \mathrm{~min}$, washed twice in water, heated at $65^{\circ} \mathrm{C}$ for $20 \mathrm{~min}$, washed again and stored at $4^{\circ} \mathrm{C}$. Microscopic examination indicated that all spore preparations were $98 \%$ free of contaminating vegetative cells, sporulating cells and germinated spores.

\subsection{Spore Viability}

Spore viability was defined as the number of colony-forming units (cfu) formed compared to the number of phase-bright spore particles plated. Purified parental 7702 and $\Delta$ ba1836 spores were tittered by visual counting using a Neubauer haemocytometer (spores/ml), then diluted and plated onto LB agar, with or without prior heat treatment at $80^{\circ} \mathrm{C}$ for $20 \mathrm{~min}$, to measure cfu (cfu/ml) [50].

\subsection{Spore Germination}

Spore germination was performed according to Fazzini et al. [51] with certain modifications. Briefly, spores were suspended at an $\mathrm{OD}_{600 \mathrm{~nm}}$ of $1.0 \mathrm{in} 1 \mathrm{ml}$ water. After heat activation at $65^{\circ} \mathrm{C}$ for $20 \mathrm{~min}$, the suspensions were centrifuged at $5900 \mathrm{~g}$ for $5 \mathrm{~min}$ and $900 \mu \mathrm{l}$ were removed. Germination of spores was initiated by the addition of $1 \mathrm{ml}$ of a mixture of $25 \mathrm{mM} \mathrm{L}$-alanine and $12.5 \mathrm{mM}$ inosine. The suspensions were incubated at $37^{\circ} \mathrm{C}$ for $120 \mathrm{~min}$. Germination was monitored by the loss of optical density at $600 \mathrm{~nm}$.

\subsection{Western Blotting Analysis}

B. anthracis cell lysates, at the time point at which GFP fluorescence signal was obtained, were separated by SDS-PAGE, blotted, and probed with the following antibodies: polyclonal rabbit anti-GFP primary antibody (Minotech) diluted 1:25,000 and monoclonal anti-rabbit IgG ( $\gamma$-chain specific) alkaline phosphatase secondary antibody (Sigma) diluted 1:3125.

\section{Results}

\subsection{BA1836 Is a Putative PDA}

The genome of $B$. anthracis Sterne 7702 sequence database revealed 12 coding sequences for putative PDAs of the CE4 family. Eleven of them exhibit more than $90 \%$ sequence identity to their homologues from B. cereus sensu stricto. For BA1836, the TMHMM [52] program predicts the presence of an $\mathrm{N}$-terminus transmembrane domain (residues 5 - 23). The TatP [7] [53] and SignalP [53] [54] programs do not predict a signal peptide. BA1836 shares $92 \%$ identity with its homologue $\mathrm{BC} 1768$ from B. cereus and displays $25 \%-30 \%$ identity with $B$. subtilis PDAs. Additionally, BA1836 shares an approximately $30 \%$ identity with 
other putative and known PDAs from $B$. anthracis.

Importantly, the sequence alignment of BA1836 (excluding residues 1 - 47) with representative members of the CE4 family [24] shows that BA1836 retains the pattern of sequence motifs (MT1-MT5) which are typical for PDAs (Figure 1). These include motif MT2, which is associated with a metal cation binding site formed in the catalytic center of the enzyme, and key catalytic residues (MT1, MT5), which occupy structurally homologous positions in CE4 esterases of known structures [55]. More specifically, Asp ${ }^{53}$ of motif MT1 and $\mathrm{His}^{196}$ of motif MT5, corresponding to the catalytic base and the catalytic acid of the deacetylation reaction respectively, are conserved in the sequence of BA1836 (Figure 1). Additionally, the highly conserved Pro $^{145}$, which we have recently demonstrated to be autocatalytically hydroxylated in the presence of molecular oxygen at the $\mathrm{C} \alpha$ atom to produce 2-hydroxyproline (2-Hyp), is found in motif MT3, in agreement with other well characterized PDAs. The self-hydroxylation of proline at the $\mathrm{C} \alpha$ atom has been shown to significantly enhance enzymatic activity [56]. The pattern of hydrophobic residues in motifs MT4 and MT5 agrees well with the patterns found in other PDAs (Figure 1).

\subsection{BA1836 Is Expressed in Stationary Phase Cells and Further Induced during Sporulation}

In order to monitor the expression of the ba1836 gene we constructed a transcriptional reporter by fusing an upstream fragment of ba1836 (containing the

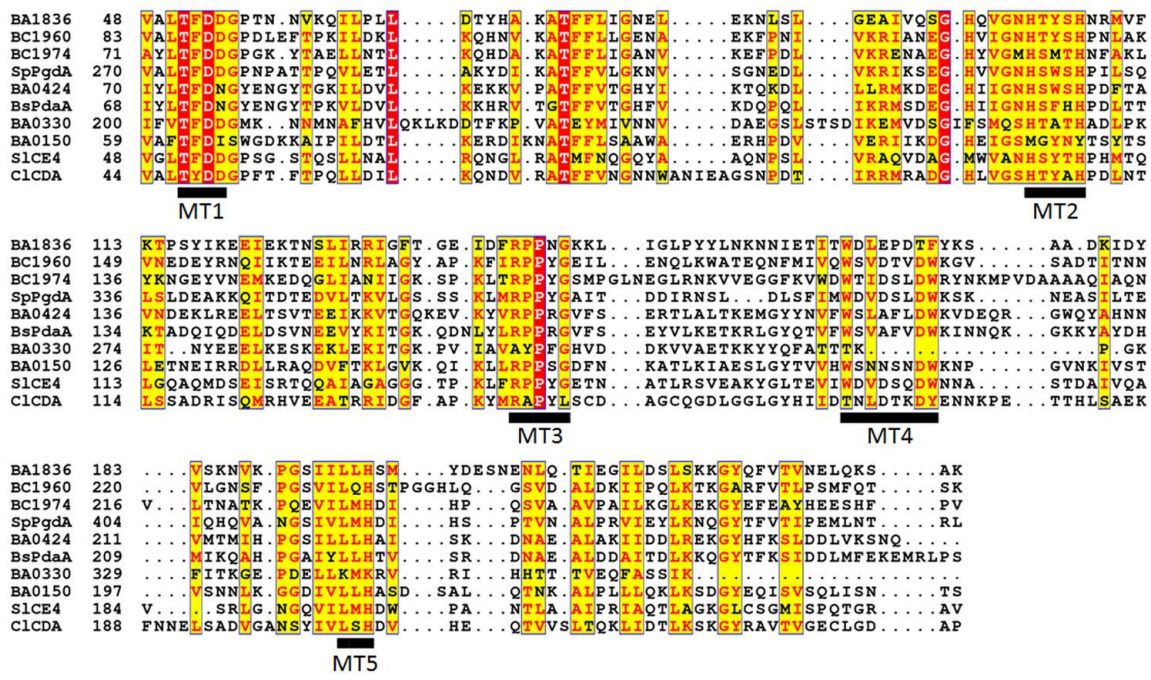

Figure 1. Sequence alignment of NodB domains. Sequence alignment of the NodB domain of BA1836 with representative members of the CE4 family including the PGDAs BC1960 [23] [57], BC1974 (B. cereus) [27] [58] and SpPgdA (S. pneumoniae) [13] [55], the MurNAc peptidoglycan deacetylases BA0424 (B. anthracis) [59] and BsPdaA (B. subtilis) [30] [60], the putative PDA BA0330 (B. anthracis) [28], the inactive PDA BA0150 (B. anthracis) [61], the acetylxylan esterase SICE4 (S. lividans) [62] and the chitin deacetylase ClCDA ( $C$. lindemuthianum) [63]. The conserved sequence motifs MT1-MT5 for this class of enzymes are shown at the bottom. The alignment was performed with T-coffee and plotted with the ESPRIT [64]. 
promoter region) with the start codon of the E. coli lacZ gene. 7702 B. anthracis cells carrying this construct were harvested at various time points during vegetative growth. As shown in Figure 2(a), BA1836 promoter driven lacZ expression was absent during exponential growth, but was rapidly induced to high level shortly after cells entered the stationary phase of growth.

We next resuspended early stationary phase $7702 \mathrm{~B}$. anthracis cells carrying this construct into sporulation-inducing medium and collected samples at various time points during sporulation. As we observed by optical microscopy, most cells were in stage II of sporulation (asymmetric division) about 8 - $12 \mathrm{~h}$ after transfer into sporulation medium, in stage III (engulfment) after 12 - 16 hours, in stage IV-V (coat and cortex assembly) after 16 - 20 hours and in stage VI-VII (spore maturation and mother cell lysis) after $20-24$ hours. We observed that expression of ba1836-lac $Z$ further increases during the early stages of sporulation (Stage I-II) (Figure 2(b)). In contrast, when exponentially growing $7702 \mathrm{~B}$. anthracis cells, in which ba1836-lac $Z$ was not expressed, were induced to sporulate, the BA1836 promoter remained silent (Figure S1). This suggests that sporulation conditions alone are not sufficient to induce BA1836 expression.

\subsection{BA1836-GFP Localizes to the Cell Periphery and Septa}

The amino acid sequence of BA1836 is predicted to include an $\mathrm{N}$-terminal membrane spanning region that is not removed by signal peptidase. In order to determine the subcellular localization of BA1836, a C-terminal $g f p$ fusion of the ba1836 gene was constructed and introduced into $B$. anthracis 7702 . We induced the expression of ba1836-gfp in B. anthracis cells that entered the stationary phase of growth, i.e., when BA1836 was normally expressed. Expression of the $g f p$-fused BA1836 was confirmed by Western blot analysis (Figure S2). The GFP tag did not affect the function of the protein, because the mutant strain transformed

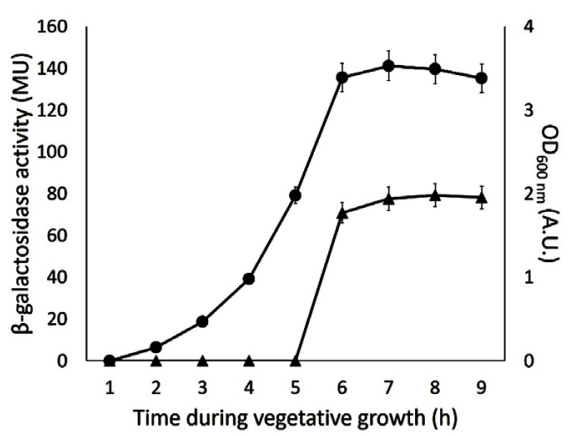

(a)

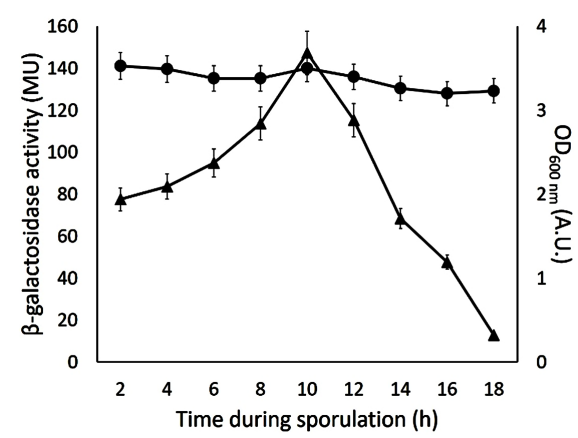

(b)

Figure 2. Expression of ba1836 gene. (a) B. anthracis 7702 strain, carrying the lac $Z$ transcriptional reporter for bal836 gene, grown in BHI (b) induction of sporulation of stationary phase cells. Samples taken at the indicated time points were assayed for $\beta$-galactosidase activity. ba1836 is expressed after cells entered stationary phase of growth and is further induced in sporulation. $(\bullet) \mathrm{OD}_{60 \mathrm{~nm}}$ (A.U.) ( $\Delta$ ) $\beta$-galactosidase activity in Miller Units (MU). Data are representative of three independent experiments, each experiment was performed in triplicates and the error bars indicate standard deviation. 
with the respective BA1836-GFP protein complemented the observed phenotypes (section: $\Delta$ ba1836 cells display severe delay in spore development and $\Delta$ ba1836 knockout strain lowers the spore germination rate). BA1836-GFP localized at the cell membrane and septa in stationary phase cells (Figure 3).

\subsection{Cells Lacking BA1836 Suffer Reduced Sporulation Fitness}

To elucidate the physiological role of BA1836, we constructed a ba1836 gene knockout in B. anthracis 7702 strain according to the method of Janes and Stibitz [34]. Mutant cells were able to grow with no obvious defect and with similar rate as wild-type cells in various liquid media (BHI and SPY broth) indicating that BA1386 is not required for growth and viability of B. anthracis cells (Figure S3(a), Figure S3(b)). $\Delta$ ba1836 knockout cells grown in SPY medium, were not sensitive to lysozyme either in the exponential or in the stationary phase of growth (Figure S4(a)) suggesting that BA1836 is not a bona fide PGDA involved in resistance to host lysozyme. The autolytic activity of $\Delta$ ba1836 and 7702 strains was tested by addition of $\mathrm{NaN}_{3}$, a known inducer of autolysis in growing cultures. $\Delta$ ba1836 cells showed decreased autolysis at these conditions compared to the parental strain (Figure S4(b)). The PG pattern from stationary phase cells of $\Delta$ ba1836 mutant was similar to that of the parental strain (Figure S5).

In order to examine the morphology of $\Delta b a 1836$ cells, we collected samples during exponential and stationary growth phase in SPY medium and visualized cells by scanning electron microscopy (SEM). $\Delta$ ba1836 daughter cells grown exponentially displayed morphologies similar to that of the parental strain, consistent with the lack of ba1836 expression under these conditions (Figure S4(c)). However, stationary phase $\Delta$ ba1836 cells displayed chains of unseparated cells $(5.15 \pm 0.14 \mu \mathrm{m}, \mathrm{n}=190)$ compared to the mostly single cell morphology (3.21 \pm $0.18 \mu \mathrm{m}, \mathrm{n}=175$ ) of the parental strain (Figure $S 4(\mathrm{c})$ ).

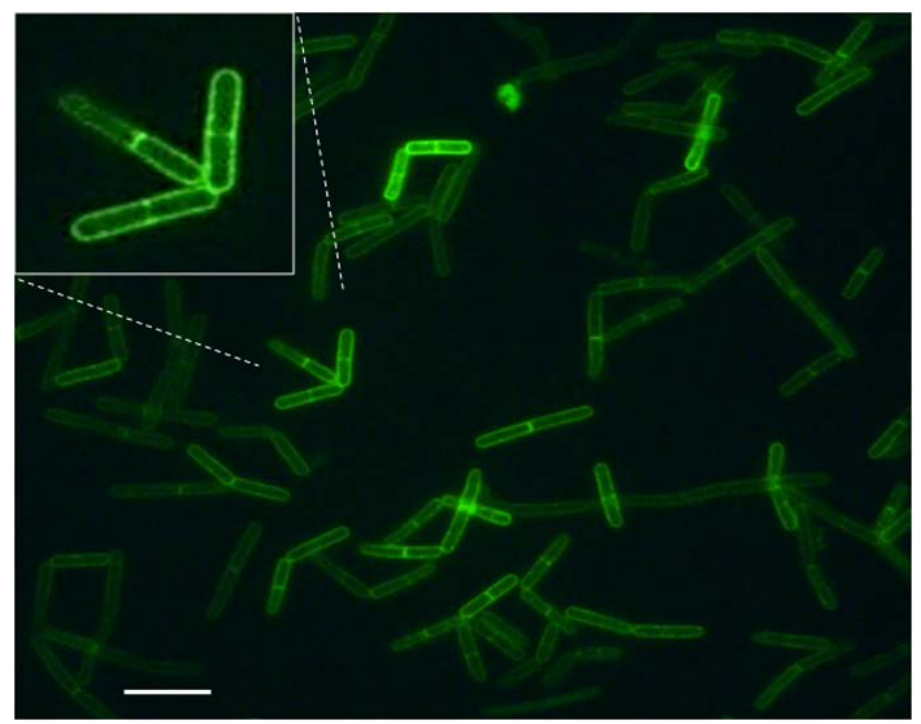

Figure 3. Localization of BA1836-GFP. BA1836-GFP localizes at the cell periphery and septa in stationary phase cells. Scale bar $10 \mu \mathrm{m}$. 
Since bal 836 gene was expressed upon entry to the stationary phase of growth and was further induced during sporulation, we next examined the morphology of spores produced by $\triangle b a 1836$ by SEM and TEM imaging. No significant differences were observed between mature spores of $\Delta b a 1836$ and the parental strain, suggesting that $\Delta$ ba1836 cells can produce morphologically and structurally normal spores with similar cortex thickness (Figure S6(a)). The efficiency of $\Delta b a 1836$ spore formation, their viability and their heat resistance was similar to that of the parental strain (Figure S6(b)). To test for a more subtle role of ba1836 in spore formation, competition experiments were conducted in which $\triangle$ ba1836 strain competed against 7702 wild type strain for several rounds of sporulation. In 7702 wild type strain, lac $Z$ is under the transcriptional control of the eag promoter. The competition experiment was initially performed with a ratio of 1:1 (wild type to mutant cells) (Figure $4(\mathrm{a})$ ) but since $\Delta$ ba1836 cells showed a severe competition deficit, the mutant cells were added in threefold excess (Figure 4(b)). Over the course of seven days of co-culturing the percentage of the mutant strain decreased from $75 \%$ to $1 \%$ of the population (Figure 4 (b)). On the contrary, $\Delta b a 1836$ mutant strain had no fitness defect under vegetative growth conditions (Figure $4(\mathrm{c})$ ). Complementation of the competition deficit under sporulation-inducing conditions of $\Delta$ ba1836 strain could not be performed since the addition of xylose to the cultures inhibited entering of cells to sporulation. These results strongly suggest that BA1836 is actively involved in sporulation and/or germination processes.

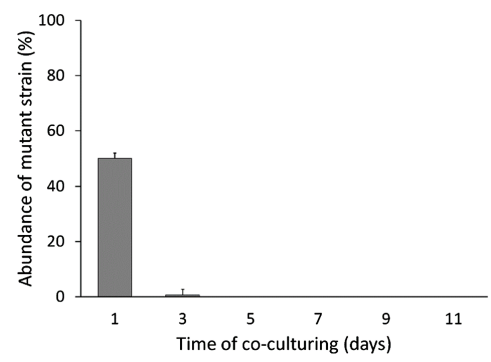

(a)

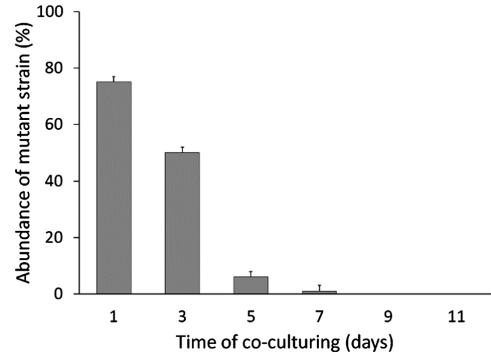

(b)

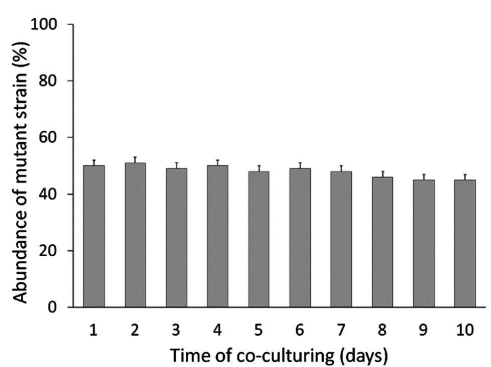

(c)

Figure 4. Competition experiment. $\triangle$ ba1836 mutant strain exhibits reduced sporulation fitness. A wild-type reference strain carrying a Peag-lac $Z$ transcriptional reporter was competed against $\Delta$ bal836 mutant in sporulation-inducing medium, starting with (a) $50 \%$ and (b) $75 \%$ mutant strain; (c) $\Delta$ ba1836 mutant strain has no fitness defect under growth conditions. Data are representative of three independent experiments, each experiment was performed in triplicates and the error bars indicate standard deviation. 


\section{5. $\Delta$ ba1836 Cells Display Severe Delay in Spore Development}

Since we observed a competition deficit under sporulation-inducing conditions of $\Delta$ ba1836 knockout cells, we next examined every stage of sporulation by optical microscopy. Interestingly, the mutant cells showed a remarkable delay in spore development (Figure 5). At 13 hours post-resuspension into sporulation-inducing medium, the majority of 7702 mother cells have engulfed the forespore (stage III of sporulation). In contrast, at the same time point the majority of the $\Delta b a 1836$ cells only entered assymetric septation (stage II of sporulation) (Figure 5). Four hours later, almost every 7702 mother cell has produced a mature forespore (stage VI of sporulation), while the majority of the $\Delta b a 1836$ mother cells have only entered stage III of sporulation (Figure 5). Mature forespores were visible in $\Delta$ ba1836 mother cells 21 hours post resuspension into sporulation-inducing medium (Figure 5). These observations show that $\Delta$ ba1836 cells display a severe delay in spore development, consistent with the expression of ba1836 in this developmental stage.

The PG pattern from mature spores of $\Delta b a 1836$ and 7702 strains were analyzed by HPLC [47]. The digestion of PG from $\Delta$ ba1836 spores with mutanolysin produced an identical overall muropeptide profile compared to PG from wild type spores, although the amount of muropeptides released from the mutant was significantly reduced (Figure 6). Expressing ba1836-gfp in $\Delta b a 1836$ restored the wild-type spore PG profile (Figure 6). Complementation was also attempted using the native protein but no expression was observed in $\Delta$ ba1836 cells (data not shown).

\section{6. $\Delta b a 1836$ Knockout Strain Lowers the Spore Germination Rate}

Finally, we determined the rate of germination of $\Delta b a 1836$ mutant strain as a

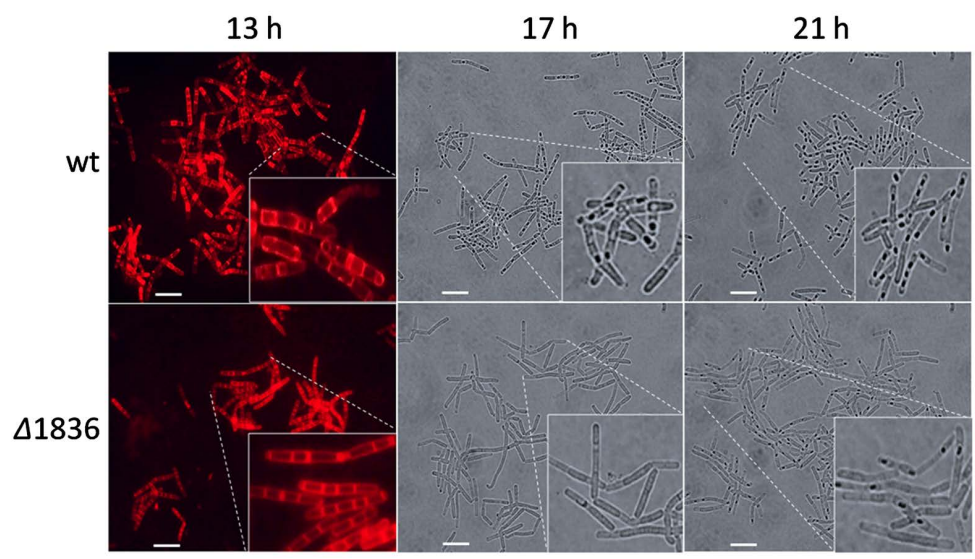

Figure 5. Phenotypic analysis of parental and mutant sporulating cells. Optical microscopy of 7702 and $\Delta$ ba1836 cells, at various time points after induction of sporulation into $\mathrm{G}$ modified medium. According to our observation, 8 - 12 hours corresponded to Stage II, 12 - 16 hours to Stage III, 16 - 20 hours to Stage IV-V and 20 - 24 hours to Stage VI of sporulation. $\Delta b a 1836$ shows a delay of spore development of approximately 4 hours. Scale bar $10 \mu \mathrm{m}$. Data are representative of three independent experiments. 
reduction in spore-specific absorbance upon the addition of $25 \mathrm{mM} \mathrm{L}$-alanine and $12.5 \mathrm{mM}$ inosine as germinants. As shown in Figure 7, when ba1836 gene was deleted, spores were capable of initiating germination but, compared to wild-type, the $\Delta$ ba1836 spores had a lower rate of germination. Fifteen minutes after the addition of germinants there was almost $40 \%$ loss of absorbance for 7702 spores compared to a $20 \%$ loss for $\Delta$ ba1836 spores. $\Delta$ ba1836 spores lost almost $40 \%$ of the absorbance after $90 \mathrm{~min}$. These results indicate that the absence of BA1836 results in a delay in germination. The rate of germination of $\triangle$ ba1836 mutant spores was partially complemented by expressing either BA1836-GFP or the predicted catalytically inactive BA1836 D53A-GFP, indicating that putative deacetylase activity is not required to complement this phenotype (Figure 7).

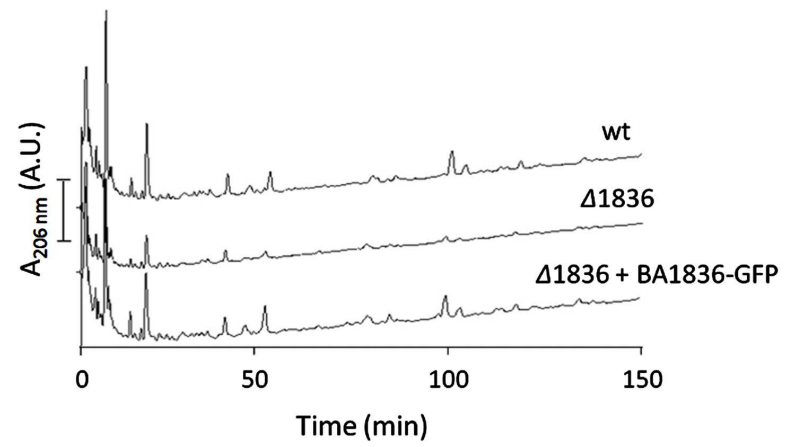

Figure 6. HPLC analysis of muropeptide pattern of peptidoglycan isolated from 7702 and $\Delta$ ba1836 mature spores. $\Delta$ ba1836 spore PG digestion with the muramidase mutanolysin produced an identical overall muropeptide profile but reduced amount of muropeptides. $\Delta$ ba1836 mutant strain complemented with BA1836-GFP recovers the phenotype. Bar, $200 \mathrm{mAU}$. Data are representative of three independent experiments.

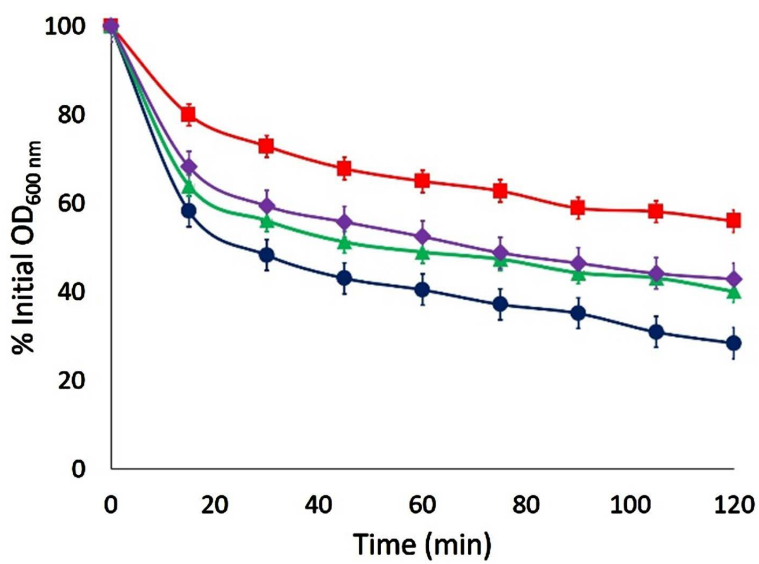

Figure 7. Germination of parental and mutant spores in response to L-ala and inosine. Spores of $7702(\bullet)$ and $\Delta$ ba1836 $(\bullet)$ were induced to germinate by the addition of L-ala and inosine. Germination was monitored by loss of absorbance at $600 \mathrm{~nm}$. $\Delta$ ba1836 shows a decreased rate of germination compared to the wild type. Mutant strain complemented with BA1836-GFP $(\Delta)$ and BA1836 D53A-GFP $(\star)$ partially recovered the phenotype. Data are representative of three independent experiments, each experiment was performed in triplicates and the error bars indicate standard deviation. 


\section{Discussions}

In this study we employed gene knock-out, protein localization, expression profile analysis as well as sporulation and germination assays to elucidate the physiological role of the putative PDA BA1836 from B. anthracis.

ba1836 expression is triggered upon entrance in the stationary phase of growth and is further induced in the early stages of sporulation, in contrast to a B. anthracis DNA microarray study which reported that ba1836 is expressed only throughout logarithmic phase of growth [65].

The $\Delta$ ba1836 mutant showed a defect in cell separation (Figure S4(a)) and a lower rate of autolysis (Figure S4(b)) compared to the wild type strain suggesting a mechanism of impaired substrate recognition by PG hydrolases that are crucial for autolysis and cell division. Reduced lysis has been similarly observed with all PDA mutants of $B$. anthracis examined so far, except $\Delta b a 1977$ [27].

Deletion of ba1836 resulted in a severe competition deficit under sporulation-inducing conditions (Figure 4(a) and Figure 4(b)). $\Delta$ ba1836 cells displayed a severe delay in sporulation (Figure 5), although mutant spores were morphologically and structurally normal and able to germinate (Figure S6(a) and Figure S6(b)).

Deletion of other genes from $B$. anthracis has been similarly reported to result in a noticeable delay in spore development which has been attributed to different reasons. Inactivation of almost each of the sensor histidine kinase genes in $B$. anthracis resulted in a delay in sporulation of the resulting mutant strains, especially the $\Delta$ ba2291 strain [66]. Similarly to ba1836, ba2291 was expressed during stationary phase of growth and was inferred to be involved in sporulation by its strong inhibition of sporulation when expressed in B. subtilis. The inhibitory activity of BA2291 has been proposed to be due to either dephosphorylation of the phosphotransferase Spo0F or the transcription factor Spo0A or sequestering one or both of these proteins, preventing access by sporulation kinases [66]. Similarly one of the three sortase mutant strains of $B$. anthracis, namely srt $C$ mutant, did not readily form spores in guinea pig tissue or sheep blood unless their vegetative forms were expressed in the presence of oxygen [67]. It is currently unclear if BA1836 is functionally linked to BA2291 or SrtC.

In repeated mutanolysin digests of spore PG from $\Delta b a 1836$ mutant, we obtained an almost identical muropeptide pattern, but a considerable lower amount of muropeptides, compared to digests of spore PG from wild-type. This could be due to a reduced amount of PG in the mutant, less efficient digestions, or both (Figure 6). The wild-type spore PG profile was partially complemented when the mutant strain was transformed with BA1836-GFP. A similar phenotype has been reported for the sporulation proteins SpoVM and SpoVS of B. subtilis [68]. The reduced PG amount of spoVM deficient spores has been attributed to incomplete cortex synthesis which was suggested to result either from its interaction with the spore coat morphogenesis protein SpoIVA [69] or the protease FtsH [70] [71]. Except from the reduced amount of spore PG, spoVS-deficient 
spores showed a delay in the initiation of sporulation. Similarly to SpoVM and SpoVS, BA1836 might have a regulatory role via its interaction with other protein(s).

Sporulation proteins appear to have mainly regulatory functions participating in protein-DNA, protein-protein and/or protein/PG interactions and only a small number of them have enzymatic activity. Many of these proteins could have lost their enzymatic activity and retained only substrate binding ability while some might have preserved the initial activity which is probably not directly relevant to their role in sporulation [72].

We were unable to purify BA1836 and perform biochemical characterization of this protein due to immediate proteolysis of the recombinant protein expressed in various $E$. coli strains (data not shown). This observation might indicate that interaction of BA1836 with other protein(s) is necessary for its stabilization against proteolysis.

The $\Delta$ ba1836 mutant strain exhibited a reduced rate of germination which was partially complemented by ba1836-gfp expression (Figure 7). To determine whether this phenotype is due to the putative de- $N$-acetylase activity, we expressed a GFP-protein fusion version whereby the catalytic aspartic acid residue has been replaced with alanine, BA1836 (D53A) (Figure 7). Remarkably, the putative inactive BA1836 version partially complemented this phenotype, indicating that it is not caused by the lack of enzymatic activity. This result suggests that BA1836 may be an inactive deacetylase version which could participate in the organization of other enzymes or proteins involved in the germination process. Although BA1836 has the characteristic sequence motifs of active PDAs (Figure 1), we cannot exclude the possibility that mutations resulting in altering BA1836 conformation had occurred, and led to steric blocking of the active site or disruption of substrate-binding sites [73].

Absence of BA1836 did not change PG deacetylation either from stationary phase of growth or spores, suggesting that it is not a PGDA and therefore even if we managed to purify the protein, it is doubtful whether we would be able to demonstrate enzymatic activity on commonly used deacetylase substrates such as $\mathrm{H}^{3}$ glycol chitin, $\mathrm{N}$-acetyl-chito-oligosaccharides and PG. This has been reported for PDAs acting on substrates other than PG, e.g. IcaB [74] and PgaB [75].

Therefore, BA1836 might have an as-yet-unidentified substrate, similarly to BA0330, and BA0331 (which also have the characteristic sequence motifs of active PDAs) [28], not directly relevant to its role in sporulation.

Presently studied putative and characterized PDAs from B. anthracis have been demonstrated to be involved in resistance to host lysozyme, stabilization of the cell wall, biogenesis of PG and for neutral polysaccharide modification and attachment to PG.

To our knowledge the sporulation specific role of BA1836 is unique among the functions of the other PDAs from B. anthracis. 


\section{Conflicts of Interest}

The authors declare no conflicts of interest regarding the publication of this paper.

\section{References}

[1] Mock, M. and Fouet, A. (2001) Anthrax. Annual Review of Microbiology, 55, 647-671. https://doi.org/10.1146/annurev.micro.55.1.647

[2] Tan, I.S. and Ramamurthi, K.S. (2014) Spore Formation in Bacillus subtilis. Environmental Microbiology Reports, 6, 212-225.

https://doi.org/10.1111/1758-2229.12130

[3] Henriques, A.O. and Moran, C.P. (2007) Structure, Assembly, and Function of the Spore Surface Layers. Annual Review of Microbiology, 61, 555-588. https://doi.org/10.1146/annurev.micro.61.080706.093224

[4] Driks, A. (2009) The Bacillus anthracis Spore. Molecular Aspects of Medicine, 30, 368-373. https://doi.org/10.1016/j.mam.2009.08.001

[5] Errington, J. (2003) Regulation of Endospore Formation in Bacillus subtilis. Nature Reviews Microbiology, 1, 117-126. https://doi.org/10.1038/nrmicro750

[6] Piggot, P.J. and Hilbert, D.W. (2004) Sporulation of Bacillus subtilis. Current Opinion in Microbiology, 7, 579-586. https://doi.org/10.1016/j.mib.2004.10.001

[7] Boneca, I.G. (2005) The Role of Peptidoglycan in Pathogenesis. Current Opinion in Microbiology, 8, 46-53. https://doi.org/10.1016/j.mib.2004.12.008

[8] Meador-Parton, J. and Popham, D.L. (2000) Structural Analysis of Bacillus subtilis Spore Peptidoglycan during Sporulation. Journal of Bacteriology, 182, 4491-4499. https://doi.org/10.1128/JB.182.16.4491-4499.2000

[9] Gilmore, M.E., Bandyopadhyay, D., Dean, A.M., Linnstaedt, S.D. and Popham, D.L. (2004) Production of Muramic Delta-Lactam in Bacillus subtilis Spore Peptidoglycan. Journal of Bacteriology, 186, 80-89. https://doi.org/10.1128/JB.186.1.80-89.2004

[10] Popham, D.L. (2002) Specialized Peptidoglycan of the Bacterial Endospore: The Inner Wall of the Lockbox. Cellular and Molecular Life Sciences, 59, 426-433. https://doi.org/10.1007/s00018-002-8435-5

[11] Dowd, M.M., Orsburn, B. and Popham, D.L. (2008) Cortex Peptidoglycan Lytic Activity in Germinating Bacillus anthracis Spores. Journal of Bacteriology, 190, 4541-4548. https://doi.org/10.1128/JB.00249-08

[12] Dworkin, J. (2014) Protein Targeting during Bacillus subtilis Sporulation. Microbiology Spectrum, 2, TBS-0006-2012.

https://doi.org/10.1128/microbiolspec.TBS-0006-2012

[13] Vollmer, W. and Tomasz, A. (2000) The pgdA Gene Encodes for a Peptidoglycan N-Acetylglucosamine Deacetylase in Streptococcus pneumoniae. The Journal of Biological Chemistry, 275, 20496-20501. https://doi.org/10.1074/jbc.M910189199

[14] Boneca, I.G., Dussurget, O., Cabanes, D., Nahori, M.A., Sousa, S., Lecuit, M., et al. (2007) A Critical Role for Peptidoglycan N-Deacetylation in Listeria Evasion from the Host Innate Immune System. Proceedings of the National Academy of Sciences of the United States of America, 104, 997-1002.

https://doi.org/10.1073/pnas.0609672104

[15] Fittipaldi, N., Sekizaki, T., Takamatsu, D., de la Cruz Dominguez-Punaro, M., Harel, J., Bui, N.K., et al. (2008) Significant Contribution of the pgdA Gene to the Virulence of Streptococcus suis. Molecular Microbiology, 70, 1120-1135. 
https://doi.org/10.1111/j.1365-2958.2008.06463.x

[16] Atrih, A. and Foster, S.J. (2001) Analysis of the Role of Bacterial Endospore Cortex Structure in Resistance Properties and Demonstration of Its Conservation amongst Species. Journal of Applied Microbiology, 91, 364-372. https://doi.org/10.1046/j.1365-2672.2001.01394.x

[17] Driks, A. (2002) Maximum Shields: The Assembly and Function of the Bacterial Spore Coat. Trends in Microbiology, 10, 251-254. https://doi.org/10.1016/S0966-842X(02)02373-9

[18] Hanna, P.C. and Ireland, J.A. (1999) Understanding Bacillus anthracis Pathogenesis. Trends in Microbiology, 7, 180-182. https://doi.org/10.1016/S0966-842X(99)01507-3

[19] Moir, A., Corfe, B.M. and Behravan, J. (2002) Spore Germination. Cellular and Molecular Life Sciences, 59, 403-409. https://doi.org/10.1007/s00018-002-8432-8

[20] Ireland, J.A. and Hanna, P.C. (2002) Amino Acid- and Purine Ribonucleoside-Induced Germination of Bacillus anthracis DeltaSterne Endospores: gerS Mediates Responses to Aromatic Ring Structures. Journal of Bacteriology, 184, 1296-1303. https://doi.org/10.1128/JB.184.5.1296-1303.2002

[21] Setlow, P. (2013) When the Sleepers Wake: The Germination of Spores of Bacillus Species. Journal of Applied Microbiology, 115, 1251-1268. https://doi.org/10.1111/jam.12343

[22] Moir, A. and Cooper, G. (2015) Spore Germination. Microbiology Spectrum, 3. https://doi.org/10.1128/microbiolspec.TBS-0014-2012

[23] Psylinakis, E., Boneca, I.G., Mavromatis, K., Deli, A., Hayhurst, E., Foster, S.J., et al. (2005) Peptidoglycan N-acetylglucosamine Deacetylases from Bacillus cereus, Highly Conserved Proteins in Bacillus anthracis. The Journal of Biological Chemistry, 280, 30856-30863. https://doi.org/10.1074/jbc.M407426200

[24] Caufrier, F., Martinou, A., Dupont, C. and Bouriotis, V. (2003) Carbohydrate Esterase Family 4 Enzymes: Substrate Specificity. Carbohydrate Research, 338, 687-692. https://doi.org/10.1016/S0008-6215(03)00002-8

[25] Kafetzopoulos, D., Martinou, A. and Bouriotis, V. (1993) Bioconversion of Chitin to Chitosan: Purification and Characterization of Chitin Deacetylase from Mucor Rouxii. Proceedings of the National Academy of Sciences of the United States of America, 90, 2564-2568. https://doi.org/10.1073/pnas.90.7.2564

[26] Tsigos, I., Martinou, A., Kafetzopoulos, D. and Bouriotis, V. (2000) Chitin Deacetylases: New, Versatile Tools in Biotechnology. Trends in Biotechnology, 18, 305-312. https://doi.org/10.1016/S0167-7799(00)01462-1

[27] Balomenou, S., Fouet, A., Tzanodaskalaki, M., Couture-Tosi, E., Bouriotis, V. and Boneca, I.G. (2013) Distinct Functions of Polysaccharide Deacetylases in Cell Shape, Neutral Polysaccharide Synthesis and Virulence of Bacillus anthracis. Molecular Microbiology, 87, 867-883. https://doi.org/10.1111/mmi.12137

[28] Arnaouteli, S., Giastas, P. andreou, A., Tzanodaskalaki, M., Aldridge, C., Tzartos, S.J., et al. (2015) Two Putative Polysaccharide Deacetylases Are Required for Osmotic Stability and Cell Shape Maintenance in Bacillus anthracis. The Journal of Biological Chemistry, 290, 13465-13478. https://doi.org/10.1074/jbc.M115.640029

[29] Balomenou, S., Koutsioulis, D., Tomatsidou, A., Tzanodaskalaki, M., Petratos, K. and Bouriotis, V. (2018) Polysaccharide Deacetylases Serve as New Targets for the Design of Inhibitors against Bacillus anthracis and Bacillus cereus. Bioorganic \& Medicinal Chemistry, 26, 3845-3851. https://doi.org/10.1016/j.bmc.2018.06.045 
[30] Fukushima, T., Yamamoto, H., Atrih, A., Foster, S.J. and Sekiguchi, J. (2002) A Polysaccharide Deacetylase Gene (pdaA) Is Required for Germination and for Production of Muramic Delta-Lactam Residues in the Spore Cortex of Bacillus subtilis. Journal of Bacteriology, 184, 6007-6015. https://doi.org/10.1128/JB.184.21.6007-6015.2002

[31] Fukushima, T., Tanabe, T., Yamamoto, H., Hosoya, S., Sato, T., Yoshikawa, H., et al. (2004) Characterization of a Polysaccharide Deacetylase Gene Homologue (pdaB) on Sporulation of Bacillus subtilis. The Journal of Biochemistry, 136, 283-291. https://doi.org/10.1093/jb/mvh151

[32] Kim, H.U. and Goepfert, J.M. (1974) A Sporulation Medium for Bacillus anthracis. Journal of Applied Bacteriology, 37, 265-267. https://doi.org/10.1111/j.1365-2672.1974.tb00438.x

[33] Sterlini, J.M. and Mandelstam, J. (1969) Commitment to Sporulation in Bacillus subtilis and Its Relationship to Development of Actinomycin Resistance. Biochemical Journal, 113, 29-37. https://doi.org/10.1042/bj1130029

[34] Janes, B.K. and Stibitz, S. (2006) Routine Markerless Gene Replacement in Bacillus anthracis. Infection and Immunity, 74, 1949-1953. https://doi.org/10.1128/IAI.74.3.1949-1953.2006

[35] Pezard, C., Berche, P. and Mock, M. (1991) Contribution of Individual Toxin Components to Virulence of Bacillus anthracis. Infection and Immunity, 59, 3472-3477.

[36] Trieu-Cuot, P., Carlier, C., Martin, P. and Courvalin, P. (1987) Plasmid Transfer by Conjugation from Escherichia coli to Gram-Positive Bacteria. FEMS Microbiology Letters, 48, 289-294. https://doi.org/10.1111/j.1574-6968.1987.tb02558.x

[37] Plaut, R.D. and Stibitz, S. (2015) Improvements to a Markerless Allelic Exchange System for Bacillus anthracis. PLoS ONE, 10, e0142758. https://doi.org/10.1371/journal.pone.0142758

[38] Fortinea, N., Trieu-Cuot, P., Gaillot, O., Pellegrini, E., Berche, P. and Gaillard, J.L. (2000) Optimization of Green Fluorescent Protein Expression Vectors for in Vitro and in Vivo Detection of Listeria monocytogenes. Research in Microbiology, 151, 353-360. https://doi.org/10.1016/S0923-2508(00)00158-3

[39] Rygus, T. and Hillen, W. (1991) Inducible High-Level Expression of Heterologous Genes in Bacillus megaterium Using the Regulatory Elements of the Xylose-Utilization Operon. Applied Microbiology and Biotechnology, 35, 594-599. https://doi.org/10.1007/BF00169622

[40] Koehler, T.M., Dai, Z. and Kaufman-Yarbray, M. (1994) Regulation of the Bacillus anthracis Protective Antigen Gene: $\mathrm{CO}_{2}$ and a Trans-Acting Element Activate Transcription from One of Two Promoters. Journal of Bacteriology, 176, 586. https://doi.org/10.1128/jb.176.3.586-595.1994

[41] Agaisse, H. and Lereclus, D. (1994) Structural and Functional Analysis of the Promoter Region Involved in Full Expression of the cryIIIA Toxin Gene of Bacillus thuringiensis. Molecular Microbiology, 13, 97-107. https://doi.org/10.1111/j.1365-2958.1994.tb00405.x

[42] Horton, R.M., Cai, Z.L., Ho, S.N. and Pease, L.R. (1990) Gene Splicing by Overlap Extension: Tailor-Made Genes Using the Polymerase Chain Reaction. Biotechniques, 8, 528-535.

[43] Camp, A.H. and Losick, R. (2009) A Feeding Tube Model for Activation of a Cell-Specific Transcription Factor during Sporulation in Bacillus subtilis. Genes \& Development, 23, 1014-1024. https://doi.org/10.1101/gad.1781709 
[44] Miller, J. (1972) Experiments in Molecular Genetics. Cold Spring Harbor Laboratory Press, Cold Spring Harbor.

[45] Traag, B.A., Pugliese, A., Eisen, J.A. and Losick, R. (2013) Gene Conservation among Endospore-Forming Bacteria Reveals Additional Sporulation Genes in $\mathrm{Ba}$ cillus subtilis. Journal of Bacteriology, 195, 253-260.

https://doi.org/10.1128/JB.01778-12

[46] Mesnage, S., Tosi-Couture, E. and Fouet, A. (1999) Production and Cell Surface Anchoring of Functional Fusions between the SLH Motifs of the Bacillus anthracis S-Layer Proteins and the Bacillus subtilis Levansucrase. Molecular Microbiology, 31, 927-936. https://doi.org/10.1046/j.1365-2958.1999.01232.x

[47] Popham, D.L., Helin, J., Costello, C.E. and Setlow, P. (1996) Analysis of the Peptidoglycan Structure of Bacillus subtilis Endospores. Journal of Bacteriology, 178, 6451-6458. https://doi.org/10.1128/jb.178.22.6451-6458.1996

[48] Bui, N.K., Eberhardt, A., Vollmer, D., Kern, T., Bougault, C., Tomasz, A., et al. (2012) Isolation and Analysis of Cell Wall Components from Streptococcus pneumoniae. Analytical Biochemistry, 421, 657-666.

https://doi.org/10.1016/j.ab.2011.11.026

[49] Mignot, T., Mesnage, S., Couture-Tosi, E., Mock, M. and Fouet, A. (2002) Developmental Switch of S-Layer Protein Synthesis in Bacillus anthracis. Molecular Microbiology, 43, 1615-1627. https://doi.org/10.1046/j.1365-2958.2002.02852.x

[50] Carr, K.A., Lybarger, S.R. anderson, E.C., Janes, B.K. and Hanna, P.C. (2010) The Role of Bacillus anthracis Germinant Receptors in Germination and Virulence. Molecular Microbiology, 75, 365-375. https://doi.org/10.1111/j.1365-2958.2009.06972.x

[51] Fazzini, M.M., Schuch, R. and Fischetti, V.A. (2010) A Novel Spore Protein, ExsM, Regulates Formation of the Exosporium in Bacillus cereus and Bacillus anthracis and Affects Spore Size and Shape. Journal of Bacteriology, 192, 4012-4021. https://doi.org/10.1128/JB.00197-10

[52] Krogh, A., Larsson, B., von Heijne, G. and Sonnhammer, E.L. (2001) Predicting Transmembrane Protein Topology with a Hidden Markov Model: Application to Complete Genomes. Journal of Molecular Biology, 305, 567-580. https://doi.org/10.1006/jmbi.2000.4315

[53] Bendtsen, J.D., Nielsen, H., Widdick, D., Palmer, T. and Brunak, S. (2005) Prediction of Twin-Arginine Signal Peptides. BMC Bioinformatics, 6, 167. https://doi.org/10.1186/1471-2105-6-167

[54] Nielsen, H. (2017) Predicting Secretory Proteins with SignalP. Methods in Molecular Biology, 1611, 59-73. https://doi.org/10.1007/978-1-4939-7015-5_6

[55] Blair, D.E., Schuttelkopf, A.W., MacRae, J.I. and van Aalten, D.M. (2005) Structure and Metal-Dependent Mechanism of Peptidoglycan Deacetylase, a Streptococcal Virulence Factor. Proceedings of the National Academy of Sciences of the United States of America, 102, 15429-15434. https://doi.org/10.1073/pnas.0504339102

[56] Fadouloglou, V.E., Balomenou, S., Aivaliotis, M., Kotsifaki, D., Arnaouteli, S., Tomatsidou, A., et al. (2017) Unusual $\alpha$-Carbon Hydroxylation of Proline Promotes Active-Site Maturation. Journal of the American Chemical Society, 139, 5330-5337. https://doi.org/10.1021/jacs.6b12209

[57] Fadouloglou, V.E., Kapanidou, M., Agiomirgianaki, A., Arnaouteli, S., Bouriotis, V., Glykos, N.M., et al. (2013) Structure Determination through Homology Modelling and Torsion-Angle Simulated Annealing: Application to a Polysaccharide Deacetylase from Bacillus cereus. Acta Crystallographica. Section D, Biological Crystallo- 
graphy, 69, 276-283. https://doi.org/10.1107/S0907444912045829

[58] Giastas, P., Andreou, A., Papakyriakou, A., Koutsioulis, D., Balomenou, S., Tzartos, S.J., et al. (2018) Structures of the Peptidoglycan N-Acetylglucosamine Deacetylase Bc1974 and Its Complexes with Zinc Metalloenzyme Inhibitors. Biochemistry, 57, 753-763. https://doi.org/10.1021/acs.biochem.7b00919

[59] Oberbarnscheidt, L., Taylor, E.J., Davies, G.J. and Gloster, T.M. (2007) Structure of a Carbohydrate Esterase from Bacillus anthracis. Proteins, 66, 250-252. https://doi.org/10.1002/prot.21217

[60] Blair, D.E. and van Aalten, D.M. (2004) Structures of Bacillus subtilis PdaA, a Family 4 Carbohydrate Esterase, and a Complex with $\mathrm{N}$-acetyl-glucosamine. FEBS Letters, 570, 13-19. https://doi.org/10.1016/j.febslet.2004.06.013

[61] Strunk, R.J., Piemonte, K.M., Petersen, N.M., Koutsioulis, D., Bouriotis, V., Perry, K., et al. (2014) Structure Determination of BA0150, a Putative Polysaccharide Deacetylase from Bacillus anthracis. Acta Crystallographica Section F: Structural Biology Communications, 70, 156-159. https://doi.org/10.1107/S2053230X13034262

[62] Taylor, E.J., Gloster, T.M., Turkenburg, J.P., Vincent, F., Brzozowski, A.M., Dupont, C., et al. (2006) Structure and Activity of Two Metal Ion-Dependent Acetylxylan Esterases Involved in Plant Cell Wall Degradation Reveals a Close Similarity to Peptidoglycan Deacetylases. The Journal of Biological Chemistry, 281, 10968-10975. https://doi.org/10.1074/jbc.M513066200

[63] Blair, D.E., Hekmat, O., Schuttelkopf, A.W., Shrestha, B., Tokuyasu, K., Withers, S.G., et al. (2006) Structure and Mechanism of Chitin Deacetylase from the Fungal Pathogen Colletotrichum lindemuthianum. Biochemistry, 45, 9416-9426. https://doi.org/10.1021/bi0606694

[64] Robert, X. and Gouet, P. (2014) Deciphering Key Features in Protein Structures with the New ENDscript Server. Nucleic Acids Research, 42, W320-W324. https://doi.org/10.1093/nar/gku316

[65] Bergman, N.H. anderson, E.C., Swenson, E.E., Niemeyer, M.M., Miyoshi, A.D. and Hanna, P.C. (2006) Transcriptional Profiling of the Bacillus anthracis Life Cycle in Vitro and an Implied Model for Regulation of Spore Formation. Journal of Bacteriology, 188, 6092-6100. https://doi.org/10.1128/JB.00723-06

[66] Brunsing, R.L., La Clair, C., Tang, S., Chiang, C., Hancock, L.E., Perego, M., et al. (2005) Characterization of Sporulation Histidine Kinases of Bacillus anthracis. Journal of Bacteriology, 187, 6972-6981. https://doi.org/10.1128/JB.187.20.6972-6981.2005

[67] Marraffini, L.A. and Schneewind, O. (2006) Targeting Proteins to the Cell Wall of Sporulating Bacillus anthracis. Molecular Microbiology, 62, 1402-1417. https://doi.org/10.1111/j.1365-2958.2006.05469.x

[68] Vasudevan, P., Weaver, A., Reichert, E.D., Linnstaedt, S.D. and Popham, D.L. (2007) Spore Cortex Formation in Bacillus subtilis Is Regulated by Accumulation of Peptidoglycan Precursors under the Control of Sigma K. Molecular Microbiology, 65, 1582-1594. https://doi.org/10.1111/j.1365-2958.2007.05896.x

[69] Ramamurthi, K.S., Clapham, K.R. and Losick, R. (2006) Peptide Anchoring Spore Coat Assembly to the Outer Forespore Membrane in Bacillus subtilis. Molecular Microbiology, 62, 1547-1557. https://doi.org/10.1111/j.1365-2958.2006.05468.x

[70] Cutting, S. anderson, M., Lysenko, E., Page, A., Tomoyasu, T., Tatematsu, K., et al. (1997) SpoVM, a Small Protein Essential to Development in Bacillus subtilis, Interacts with the ATP-Dependent Protease FtsH. Journal of Bacteriology, 179, 5534-5542. https://doi.org/10.1128/jb.179.17.5534-5542.1997 
[71] Prajapati, R.S., Ogura, T. and Cutting, S.M. (2000) Structural and Functional Studies on an FtsH Inhibitor from Bacillus subtilis. Biochimica et Biophysica Acta, 1475, 353-359. https://doi.org/10.1016/S0304-4165(00)00089-1

[72] Galperin, M.Y., Mekhedov, S.L., Puigbo, P., Smirnov, S., Wolf, Y.I. and Rigden, D.J. (2012) Genomic Determinants of Sporulation in Bacilli and Clostridia: Towards the Minimal Set of Sporulation-Specific Genes. Environmental Microbiology, 14, 2870-2890. https://doi.org/10.1111/j.1462-2920.2012.02841.x

[73] Adrain, C. and Freeman, M. (2012) New Lives for Old: Evolution of Pseudoenzyme Function Illustrated by iRhoms. Nature Reviews Molecular Cell Biology, 13, 489-498. https://doi.org/10.1038/nrm3392

[74] Pokrovskaya, V., Poloczek, J., Little, D.J., Griffiths, H., Howell, P.L. and Nitz, M. (2013) Functional Characterization of Staphylococcus epidermidis IcaB, a de-N-Acetylase Important for Biofilm Formation. Biochemistry, 52, 5463-5471. https://doi.org/10.1021/bi400836g

[75] Little, D.J., Poloczek, J., Whitney, J.C., Robinson, H., Nitz, M. and Howell, P.L. (2012) The Structure- and Metal-Dependent Activity of Escherichia coli PgaB Provides Insight into the Partial de-N-acetylation of Poly- $\beta-1,6-\mathrm{N}$-acetyl-D-glucosamine. The Journal of Biological Chemistry, 287, 31126-31137. https://doi.org/10.1074/jbc.M112.390005 


\section{Supporting Information}

Table S1. List of strains and plasmids used in the present study.

\begin{tabular}{|c|c|c|}
\hline Strains, plasmids & Description & Source/Reference \\
\hline \multicolumn{3}{|l|}{ Strains } \\
\hline \multicolumn{3}{|l|}{ E. coli } \\
\hline $\mathrm{DH} 5 \alpha$ & $\begin{array}{c}\text { F-80dlacZ M15 (lacZYA-argF) U169 recA1 } \\
\text { endA1hsdR17 (rk-, mk+) phoAsupE44 -thi-1 gyrA96 relA1 }\end{array}$ & Novagen \\
\hline GM48 & $\begin{array}{c}\text { thr-1, araC14, leuB6 (Am), fhuA31, lacYl, tsx-78, } \\
\text { gln } X 44 \text { (AS), galK2 (Oc), galT22, } \lambda^{-}, \text {dcm-6, dam-3, thiE1 }\end{array}$ & $\begin{array}{l}\text { Coli Genetic Stock } \\
\text { Center (CGSC) }\end{array}$ \\
\hline HB101 & F- hsd-20 recA13 ara-14 proA2 lacYl gal K2 rpsL20 (Str) xyl-5 mtl-1 supE44 & {$[36]$} \\
\hline \multicolumn{3}{|l|}{ B. anthracis } \\
\hline 7702 & $\mathrm{pXO}^{+}, \mathrm{pXO} 2^{-}$ & {$[35]$} \\
\hline \multicolumn{3}{|l|}{ Plasmids } \\
\hline pGEM T-Easy & Cloning vector & Promega \\
\hline pNF8 & pAT18 $\Omega($ Pdlt $\Omega$ gfp-mut1) & {$[38]$} \\
\hline pWH1520 & Cloning vector & Mobitec \\
\hline pHT304-18Z & Promoterless lac $Z$ vector & [41] \\
\hline pRP1028 & $\mathrm{Tm}^{\mathrm{s}}$ allelic-exchange vector & {$[37]$} \\
\hline pSS4332 & I-SceI expression vector & [37] \\
\hline
\end{tabular}

Table S2. List of oligonucleotides used in the present study.

\begin{tabular}{cc}
\hline Oligonucleotides & Sequence $\left(\mathbf{5}^{\prime} \rightarrow \mathbf{3}^{\prime}\right)$ \\
\hline Peag-FW & CCCAAGCTTTTTAGGTGATGAAGCGGAAAT \\
Peag-REV & CGGGATCCTTTATAAATTTCCTCCTTCAG \\
Up1836-pHT304-18Z-HindIII-FW & CCCAAGCTTCGTTATTTGCCCAAGATG \\
Up1836-pHT304-18Z-BamHI-REV & CGGGATCCAAAGCAACCTCACTATATTTT \\
bal836-FW-BamHI & CGGGATCCATGAAAAAGAAAATAATCATTACAATC \\
ba1836-REV-NruI & TCGCGACGGGCCCGGGCCTTTTGCACTTTTTTGTAATTCATTTAC \\
ba1836D53A-FW & TAACTTTTGCTGATGGCCC \\
bal836D53A-REV & GGGCCATCAGCAAAAGTTA \\
Upstream1836-FW & CCAAGCTTCCATATATCCAATACGGGCAAA \\
Upstream1836-REV & CCCCCGGGAACGATTGTAATGATTATTTTCTTTTTC \\
Downstream1836-FW & CCCCCGGGAAGAAGGGCTATCAGTTCGTAACA \\
Downstream1836-REV & CGCGGATCCAGTTTACCGCGTTCAGCATT \\
\hline
\end{tabular}




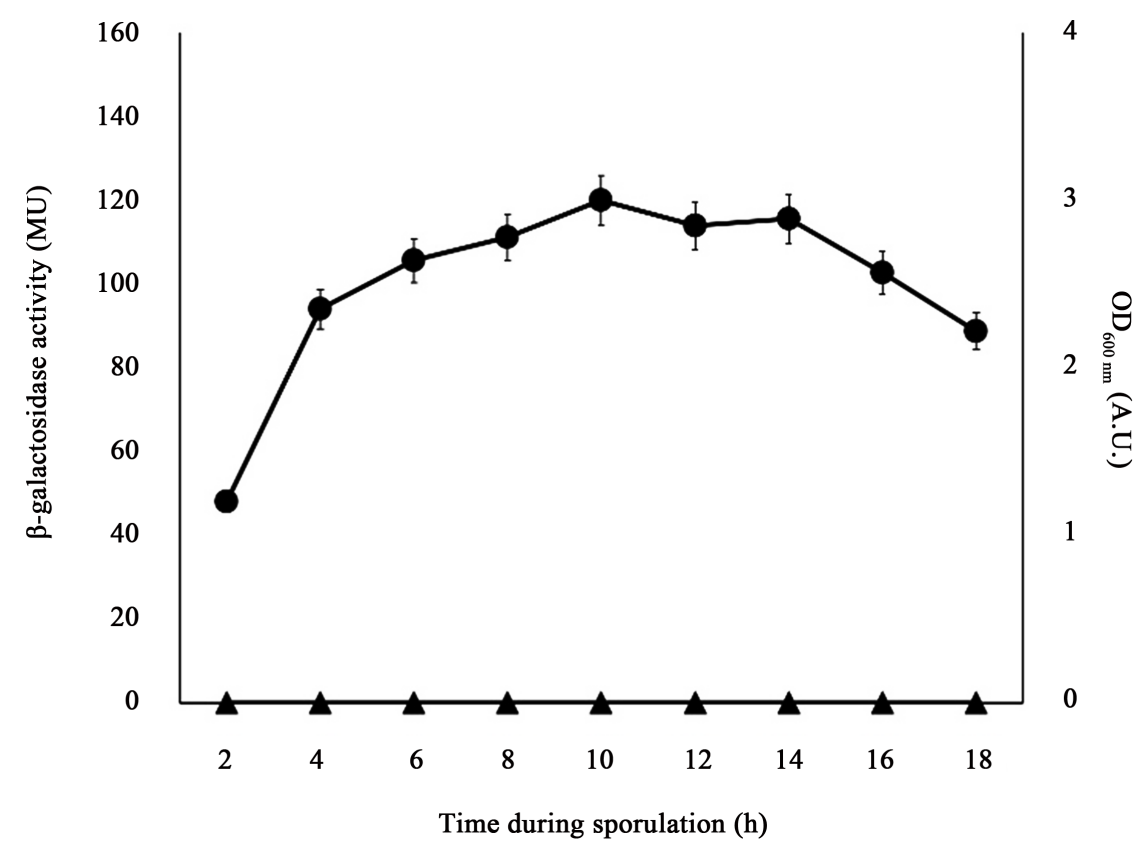

Figure S1. Expression of ba1836 gene following induction of sporulation of exponentially phase cells into $\mathrm{G}$ modified medium. Samples taken at indicated time points were assayed for $\beta$-galactosidase activity. (•) $\mathrm{OD}_{60 \mathrm{~nm}}$ (A.U.) and ( $\left.\Delta\right) \beta$-galactosidase activity of $7702 \mathrm{~B}$. anthracis cells in Miller Units (MU).

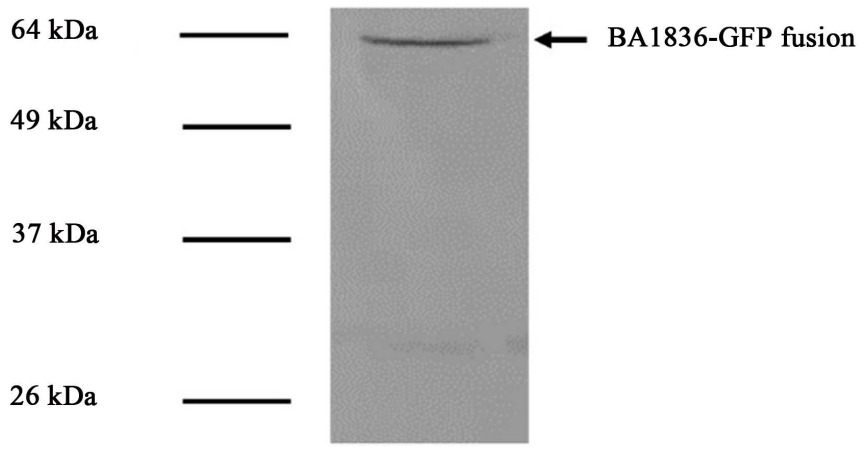

Figure S2. Western blot analysis of lysates of 7702 cells expressing ba1836-gfp during stationary phase of growth using a polyclonal anti-GFP antibody.

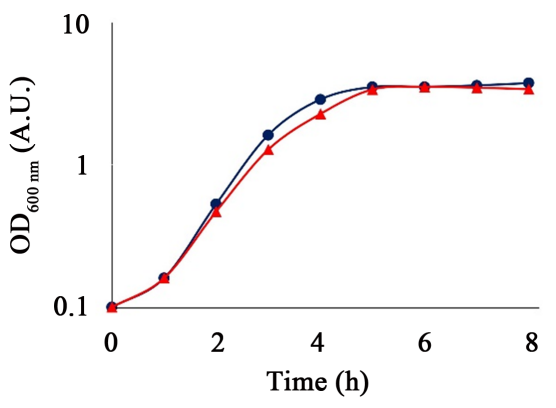

(a)

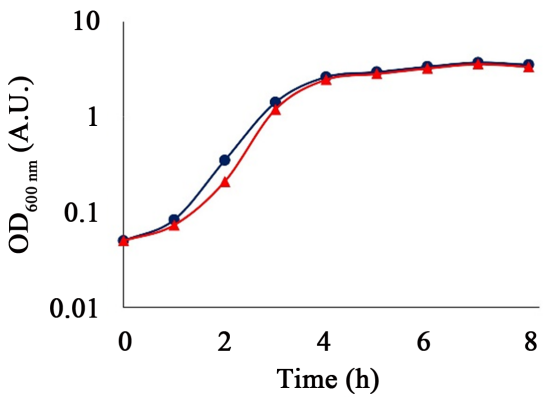

(b)

Figure S3. Growth curves of B. anthracis parental and mutant strains. Cultures of 7702 $(\bullet)$ and $\Delta$ ba1836 mutant $(\Delta)$ strains were grown in (a) BHI and (b) SPY liquid broth at $37^{\circ} \mathrm{C}$. Cell growth was monitored at $600 \mathrm{~nm}$. 


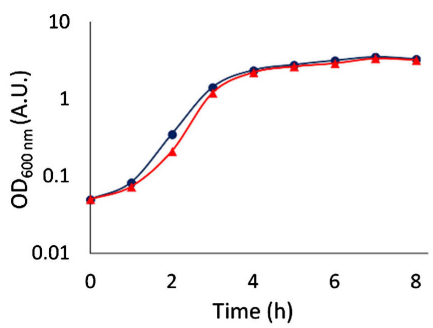

(a)
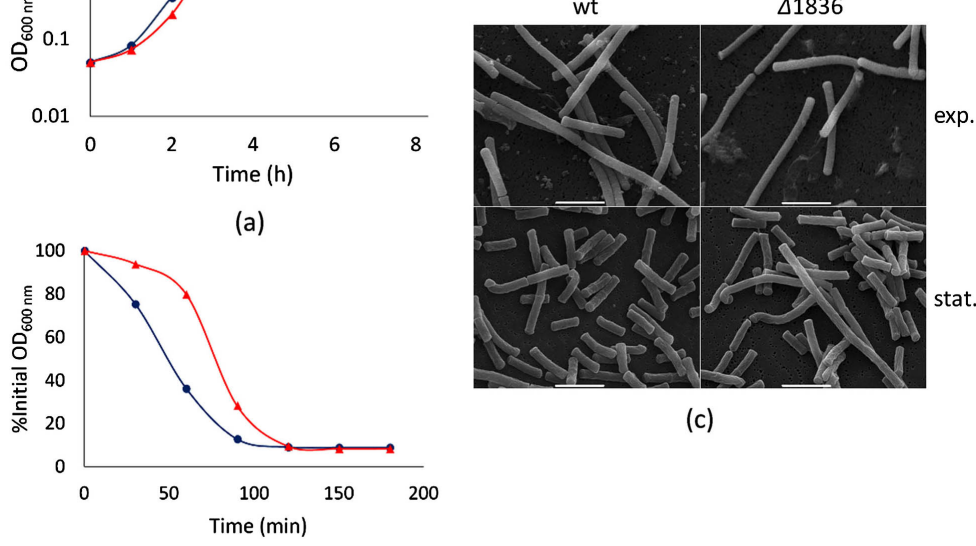

(c)

(b)

Figure S4. Lysozyme sensitivity, autolysis rate and morphology of parental and mutant strains. (a) Effect of lysozyme on $7702(\bullet)$ and $\Delta$ ba1836 mutant ( $\bullet$ ) strains. Strains were grown in SPY liquid broth at $37^{\circ} \mathrm{C} . \Delta b a 1836$ mutant is not affected by the addition of lysozyme; (b) Autolysis rate of $7702(\bullet)$ and $\Delta$ bal836 ( $\Delta$ ) cells. Cell lysis was monitored by loss of absorbance at $600 \mathrm{~nm}$. $\Delta$ ba1836 strain is affected by autolysis. (c) SEM of wild type 7702 and $\Delta$ bal 836 cells during exponential (exp.) and stationary (stat.) phase of growth. $\Delta$ ba1836 cells exhibit longer chains of daughter cells compared to the wild type only during stationary phase of growth. Scale bar $5 \mu \mathrm{m}$.

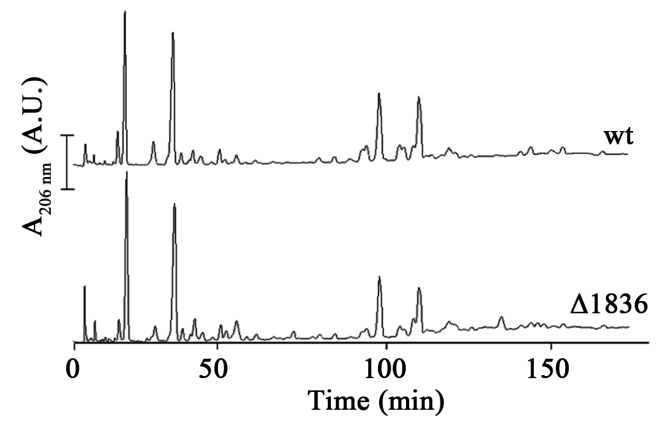

Figure S5. HPLC analysis of muropeptide pattern of PG isolated from 7702 and $\Delta b a 1836$ cells during stationary phase of growth. Bar, $200 \mathrm{mAU}$.

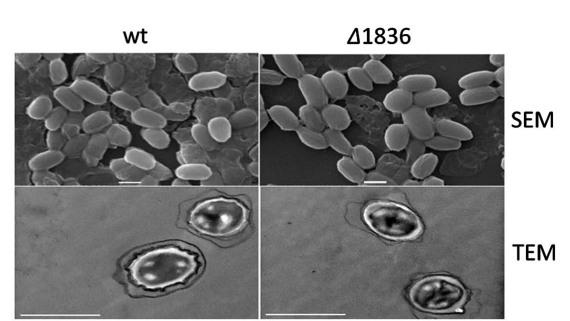

(a)

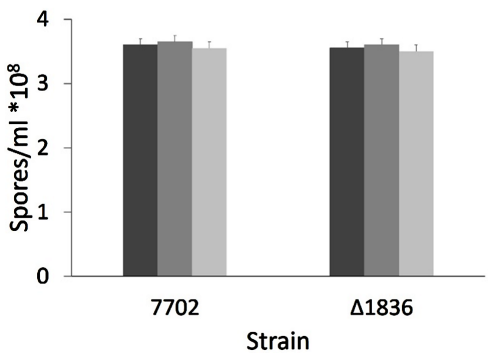

(b)

Figure S6. (a) Examination of morphology and structure of parental 7702 and mutant $\triangle$ ba1836 mature spores using SEM and TEM. Scale bar $1 \mu \mathrm{m}$. (b) Spore formation, viability and heat resistance of 7702 and $\Delta$ bal836 spores. ( $\square$ ) spores/ml ( $\square$ ) CFU/ml ( $\square$ ) $\mathrm{CFU} / \mathrm{ml}$ after heat-treatment of spores. 